\title{
Arama Motoru Optimizasyonu (SEO) Analiz Skoru ile Sıralama İlişkisi: Google Lighthouse (The Relationship Between Search Engine Optimization (SEO) and Ranking: Google Lighthouse)
}

\section{Doğuş YÜKSEL iD a Kubilay SÜMBÜLTEPE iD b Metehan TOLON iD c}

a Ostim Teknik Üniversitesi, Meslek Yüksekokulu, Pazarlama ve Reklamcılık Bölümü, Ankara, Türkiye. dogus.yuksel@ostimteknik.edu.tr

b Ankara Hacı Bayram Veli Üniversitesi, Lisansüstü Eğitim Enstitüsü, Ankara, Türkiye. kubilay.sumbultepe@hbv.edu.tr

c Ankara Hacı Bayram Veli Üniversitesi İktisadi ve İdari Bilimler Fakültesi, Ankara, Türkiye. metehan.tolon@hbv.edu.tr

\begin{tabular}{|c|c|}
\hline MAKALE BİLGİSİ & ÖZET \\
\hline $\begin{array}{l}\text { Anahtar Kelimeler: } \\
\text { Arama motoru } \\
\text { optimizasyonu (SEO) } \\
\text { Dijital pazarlama } \\
\text { SEO analizi }\end{array}$ & $\begin{array}{l}\text { Amaç - Arama motoru optimizasyonu (SEO), işletmelerin benimsediği dijital pazarlama stratejilerinden } \\
\text { biridir. İşletmeler, organik arama sonuçlarında daha iyi performans elde edebilmek için SEO çalışmaları } \\
\text { gerçekleştirmektedir. } 2019 \text { itibariyle Türkiye'de pazarın \%87,14'ünü elinde bulunduran arama motoru } \\
\text { Google, web sayfalarının kalitesini artırmak için Lighthouse aracını geliştirmiştir. İşletmeler tarafından } \\
\text { yoğunlukla kullanılan Lighthouse, site içi SEO'yu ölçen bir analiz gerçekleştirmektedir ve analiz } \\
\text { sonucunda bir SEO skoru ortaya koymaktadır. Çalışmada, Lighthouse analiz aracının ortaya koyduğu } \\
\text { SEO skorunun, sıralama ile ilişkisinin tespit edilmesi amaçlanmıştır. }\end{array}$ \\
\hline $\begin{array}{l}\text { Gönderilme Tarihi } 2 \text { Nisan } \\
2020 \\
\text { Revizyon Tarihi } 15\end{array}$ & $\begin{array}{l}\text { Yöntem - Araştırmada kullanılmak üzere anahtar kelimelere ihtiyaç duyulmuştur. Google Trends } \\
\text { aracılığı ile elde edilen veri kullanılarak alışveriş kategorisinde Türkiye'de son } 12 \text { ayda en çok aranan } \\
\text { ürün isimleri tespit edilmiştir. Tespit edilen anahtar kelimelerin kullanıldığı her bir sorgu sonucunda, } \\
\text { organik olarak sıralanan yirmi web sayfasının SEO analizi Lighthouse ile gerçekleştirilmiştir. Ortaya } \\
\text { çlkan analiz sonuçları ile sıralama arasındaki ilişki Pearson korelasyon analizi ile ölçülmüştür. }\end{array}$ \\
\hline $\begin{array}{l}\text { Kabul Tarihi } 20 \text { Haziran } \\
2020\end{array}$ & $\begin{array}{l}\text { Bulgular - Araştırmada Lighthouse SEO skoru ile sıralama arasındaki negatif yönlü zayıf bir ilişkinin } \\
\text { olduğu ortaya koyulmuştur. } 160 \text { adet web sayfası analiz edilmiş ve analiz edilen web sayfalarının } \\
\% 97,5^{\prime} \text { inin URL'sinde anahtar kelimenin bulunduğu tespit edilmiştir. }\end{array}$ \\
\hline $\begin{array}{l}\text { Makale Kategorisi: } \\
\text { Araştırma Makalesi }\end{array}$ & $\begin{array}{l}\text { Tartışma - Elde edilen bulgular, işletmelerin, SEO çalışmalarına yön verecek sonuçlar ortaya çıkarmıştır. } \\
\text { İşletmelerin Lighthouse analiz aracından } 100 \text { puan ve } 100 \text { puana yakın sonuçlar alması durumunda dahi } \\
\text { bununla yetinmeyip, SEO çalışmalarına devam etmeleri önerilmiştir. Ayrıca site içi SEO faktörlerinin } \\
\text { sıralama ile zayıf bir ilişkisi olması sonucunda site dışı SEO'nun işletmeler açısından daha önemli } \\
\text { olduğu varsayımında bulunulmuştur. }\end{array}$ \\
\hline ARTICLE INFO & ABSTRACT \\
\hline $\begin{array}{l}\text { Keywords: } \\
\text { Search engine } \\
\text { optimization (SEO) } \\
\text { Digital marketing } \\
\text { SEO analysis }\end{array}$ & $\begin{array}{l}\text { Purpose - Search engine optimization (SEO) is one of the digital marketing strategies adopted by } \\
\text { companies. Businesses carry out SEO studies to achieve better performance in organic search results. As } \\
\text { of } 2019 \text {, the search engine Google possessing } 87.14 \% \text { of the market in Turkey has developed the } \\
\text { Lighthouse tool to improve the quality of web pages. Lighthouse, extensively utilized by businesses, } \\
\text { performs an analysis that measures on-page SEO and provides a SEO score at the end of the analysis. In } \\
\text { the present study, it is aimed to determine the relationship between the SEO score provided by the } \\
\text { Lighthouse analysis tool and Google rankings. }\end{array}$ \\
\hline $\begin{array}{l}\text { Received } 2 \text { April } 2020 \\
\text { Revised } 15 \text { June } 2020 \\
\text { Accepted } 20 \text { June } 2020\end{array}$ & $\begin{array}{l}\text { Design/methodology/approach - Keywords have been needed to be used in the research. Using data } \\
\text { from Google Trends, the top-searched product names under the shopping category in the last } 12 \text { months } \\
\text { in Turkey have been identified. As a result of each search containing the predetermined keywords, the } \\
\text { SEO analysis of twenty web pages which were organically ranked has been carried out with Lighthouse. } \\
\text { The relationship between the emerging results of the analysis and Google rankings has been measured } \\
\text { by Pearson correlation analysis. }\end{array}$ \\
\hline Research Article & $\begin{array}{l}\text { Findings - The research reveals that there is a weak negative correlation between Lighthouse SEO score } \\
\text { and Google rankings. } 160 \text { web pages have been analyzed and in the URL's of } 97.5 \% \text { of the analyzed web } \\
\text { pages have been found to include the keywords. } \\
\text { Discussion - The findings have revealed results that will direct the SEO studies of the companies. It is } \\
\text { recommended that even if businesses score } 100 \text { or closer to } 100 \text { at Lighthouse analysis, they should not } \\
\text { settle for this and they should continue their SEO studies. Besides, as a result of the weak correlation } \\
\text { between on-page SEO factors and Google ranking, it is assumed that off-page SEO is more valuable for } \\
\text { businesses. }\end{array}$ \\
\hline
\end{tabular}

\section{Önerilen Atıf/Suggested Citation}

Yüksel, D., Sümbültepe, K., Tolon, M. (2020). Arama Motoru Optimizasyonu (SEO) Analiz Skoru ile Sıralama İlişkisi: Google Lighthouse, İşletme Araştırmaları Dergisi, 12 (2), 2113-2125. 


\section{Giriş}

Arama motorları teknolojinin gelişmesiyle birlikte gündelik hayatımızın vazgeçilmez bir parçası haline gelmiştir. Bilgiye ulaşmanın en basit ve hızlı yollarından biri arama motorlarını kullanmaktır. Google'daki kullanıcılar, bilgiye ulaşmak için 2019 yılı itibariyle dakikada 3,8 milyon arama sorgusu gerçekleştirmektedir. (Statista, 2019). Buradan hareketle, arama motorları işletmeler için yeni bir pazarlama kanalı haline gelmiştir. Dijital pazarlama alanında işletmelerin odaklandığı konulardan bir tanesi arama motoru optimizasyonudur (search engine optimization, SEO). Arama motorlarında sonuçlar, reklamlar ve organik sonuçlar olmak üzere ikiye ayrılmaktadır. Organik arama sonuçları arama motorunun kendi algoritması ile sıraladığı ve ücret karşılığı değişmeyen sonuçları kapsamaktadır. SEO, organik arama sonuçlarında daha yüksek performans gösterme odaklı yapılan optimizasyon çalışmalarıdır. Kullanıcılar, reklamlar yerine organik bağlantılara daha fazla güvenme eğiliminde olduğu için işletmeler, genellikle arama motoru reklamları yerine arama motoru optimizasyonu tekniklerini tercih ederek organik sıralama sonuçlarında görünürlüklerini artırmaya çalışırlar (Berman ve Katona, 2013).

İşletmelerin SEO konusunda yaptığı yatırımlar, diğer tanıtım ve pazarlama türlerine yapılan yatırımlara kıyasla uygun maliyetler ile yüksek miktarda maddi getiri sağlayan yatırımlardır (Vuran ve Alpkoçak, 2020). Bu nedenle, SEO için ortaya koyulan dijital pazarlama çabalarının ve performansın ölçümlenmesi işletmeler açısından önemli bir konudur. İşletmeler SEO ile ilgili durum analizi yaparken, çeşitli SEO analiz araçlarından faydalanmaktadır. SEO analiz araçları web sayfalarının, site içi ve site dışı performansını analiz etmektedir. Araçlar, yapılan analiz sonrasında analize tabi tutulan sayfaya bir SEO skoru vermektedir. Bu konuda en bilinen ve yayın şekilde kullanılan araçlardan bir tanesi Google Lighthouse'dur. İşletmeler SEO çalışmaları gerçekleştirirken Google Lighthouse SEO skorunu göz önünde bulundurmaktadır. Google Lighthouse analiz aracı kullanılırken, SEO skoru ile sıralama arasında zaman zaman tutarsız ilişkiler bulunduğu tespit edilmiştir. Bu nedenle makalenin araştırma sorusu “Google Lighthouse SEO skoru ile sıralama ilişkili midir?" olarak belirlenmiştir. Araştırmanın temel amacı Google Lighthouse SEO skoru ile sıralama arasındaki ilişkinin yönünün ve kuvvetinin tespit edilmesidir. Bu amaca ulaşabilmek için doğrudan Google tarafından yayınlanmış veri ve analiz araçları ile araştırma yürütülmüştür. Literatürde söz konusu değişkenleri bir arada inceleyen bir çalışmanın olmaması nedeniyle, yapılan çalışmanın dijital pazarlama alanına katkı sağlayacağı düşünülmektedir. Ek olarak, yapılan araştırma, işletmelerin SEO çalışmalarını daha verimli bir şekilde gerçekleştirmesine yönelik sektörel anlamda da katkılar sunmaktadır.

\section{Literatür}

\subsection{Arama Motorları}

Arama motorları, aranan terimleri (anahtar kelimeler) esas alarak internet veri tabanındaki bilgileri tarayan ve bunun sonucunda bir sonuç sıralaması yapan web tabanlı yazılım programlarıdır (Seymour, vd., 2011:47). Milyonlarca sorgu günlük olarak arama motorlarına gönderilir ve kullanıcılar yüksek kalite beklentisine sahiptir. Kullanıcıların beklentilerini karşılamak için arama motorları, en kaliteli web sayfalarını kullanıcılar ile buluşturacak algoritmalar geliştirmektedir. (Baeza-Yates vd., 2007:183). Arama motorlarının çalışma süreci; arama motoru robotlarının web sayfalarından veri derlemesi, derlenen verinin veri tabanında depolamasi, kullanıcıların bir sorgu gerçekleştirdiğinde depolanan veriyi incelemesi ve anahtar kelime ile en alakalı sonuçların sıralanması olarak açıklanabilir (Atay vd., 2010:10).

Karakteristik olarak, arama motoru sonuç sayfaları (search engine result page, SERP), organik sonuçlardan ve sponsorlu bağlantılardan oluşur (Höchstötter ve Lewandowski, 2009:3). Organik bağlantılar ücretsizdir. Sponsorlu bağlantılar ise kullanıcıların bağlantıya her tıkladığında, reklamverenlerden ücret alınması üzerine kurgulanmıştır. Arama motorları için ana gelir kaynağı arama motoru reklamlarıdır (De Corniere, 2016:156). Günümüzde Google SERP'te kullanıcılar haritalar, görseller, alışveriş, videolar, haberler, uçuş arama, kitap ve finans alanları ile de karşılaşmaktadır.

\subsection{Arama Motoru Optimizasyonu (SEO)}

SEO, en yalın tanımıyla, web sayfalarının organik arama sonuçlarında daha iyi performans göstermesi için yapılan çalışmaların tümüne verilen isimdir (Yüksel ve Tolon, 2019). Genel olarak, SEO site içi ve site dışı olmak üzere ikiye ayrılır. Site içi SEO, sitenin kendi yazılımı ve içeriği ile ilgili optimizasyonları içermektedir. Site içi SEO işlemleri, dosya boyutlarının minimize edilmesi, resimlerin açıklamarını içeren alt etiketlerinin 
yazılımda bulunması, sayfa başlık ve açıklamalarının kurallara uygun bir şekilde oluşturulması gibi faktörlerin iyileştirilmesini kapsamaktadır.

Site dışı optimizasyon ise yalnızca sayfa dışındaki koşullarla ilişkilidir. Web sayfalarının sıralamasını etkileyen site dışı faktörlerin iyileştirilmesini ve oluşturulmasını ifade etmektedir. Site dışı SEO işlemleri, sayfaya bağlanan diğer web sayfalarının miktarı, kalitesi, popülaritesi ve sayfa ile alakası gibi faktörlerin oluşturulmasını ve iyileştirilmesini kapsamaktadır (Dunford II, 2008:29). Site içi ve site dışında gerçekleştirilen SEO çalışmaları, arama motorlarındaki görünürlüğünü arttırmanın yanı sıra, işletmelerin marka imajının geliştirilmesine yönelik katkılar ortaya çıarmaktadır.

Optimizasyon çalışmalarından önce işletme yeteneklerini bilmek, müşterileri ve pazarı tanımak oldukça önemlidir. Bir sayfadaki her kelime için SEO çalışması yapmak mümkün değildir. Bu nedenle, içeriği en doğru şekilde temsil eden beş ila on anahtar kelime seçmek önem taşımaktadır. Ayrıca, optimizasyon her zaman hedef kitle tarafından aranması muhtemel sorgulara göre gerçekleştirilmektedir (Zilincan, 2015).

İşletmeler hedefledikleri anahtar kelimelerde en üst sıralarda çıkmak için bir rekabet halindedir. Rekabet üstünlügü sağlamak amacıyla optimizasyon çalışmaları yapmaktadırlar. Yapılan optimizasyon çalışmaları arasında bir takım temel SEO kuralları bulunmaktadır. İşletmelerin bu kuralları uygulama konusunda ne durumda olduklarını tespit etmek için bir analiz aracına ihtiyaçları bulunmaktadır. Bu ihtiyacı karşılamak amacıyla geliştirilmiş ücretli ve ücretsiz SEO analiz araçları bulunmaktadır.

\subsection{Lighthouse}

Lighthouse, Google tarafından web sayfalarının kalitesini arttırmak için oluşturulmuş bir analiz aracıdır. Açık kaynaklı ve otomatikleştirilmiş bir yapıya sahiptir (Google, 2019). Lighthouse aracı, analizlerini; performans, en iyi uygulamalar, erişilebilirlik ve SEO konu başlıklarında gerçekleştirmektedir. Doğrudan Google tarafından geliştirilmiş bir analiz aracı olması nedeniyle oldukça yaygın bir şekilde kullanılmaktadır.

Araç iki yöntem ile çalışmaktadır. Bunlardan ilkine Google Chrome tarayıcısında "Görüntüle > Geliştirici > Geliştirici Araçları" yolu izlenerek, Audits sekmesinden ulaşılmaktadır. İkinci yöntem ise tarayıcı eklentisidir. Lighthouse aracının bir Google Chrome tarayıcı eklentisi bulunmaktadır. Bu eklenti sayesinde daha ulaşılabilir bir metot ile web sayfalarının analizi yapılmaktadır. Lighthouse, herhangi bir kişi tarafından herhangi bir web sayfasına uygulanabilir. Analizin gerçekleştirilmesi için web sayfası ile ilgili bir yönetim paneli ya da ftp bilgisine ihtiyaç duyulmamaktadır. Bu bilgiler sitelerin içeriklerini yönetmek ya da yazılımını değiştirmek için ihtiyaç duyulan kullanıcı adı ve şifre bilgileridir.

Lighthouse SEO skorunu oluştururken ondört farklı kritere göre web sayfalarını analiz etmektedir. Bu kriterler şunlardır (Google, 2019);

- Genişlik veya başlangıç ölçeği olan bir <meta name = "viewport"> etiketine sahip,

- Belgenin <title> öğesi varlığı,

- Belgenin meta açıklaması varlığı,

- Sayfada başarılı HTTP durum kodu varlığı,

- Bağlantılarda açıklayıcı metin varlığı,

- Sayfanin dizine eklenmesi ile ilgili engel durumu,

- Geçerli bir robots.txt dosyası varlığı,

- Görüntü öğelerinin [alt] nitelikleri varlığı,

- Geçerli bir hreflang varlığ1,

- Okunabilir, \% 100 okunaklı yazı tipi boyutları kullanımı,

- Eklenti önlemeleri,

- Dokunulabilir hedeflerin uygun boyutta olması,

- Yapısal verinin geçerliliği,

- Geçerli bir rel = canonical değeri varlığı.

$\mathrm{Bu}$ faktörlerin Google tarafından seçilmiş olması, Google’ın önem verdiği temel SEO faktörlerini ortaya koymaktadır. Ayrıca günümüzde sayısız SEO faktörünün varlığı göz önünde bulundurulduğunda, Lighthouse aracı ile ölçümlenen sadece ondört faktörün seçilmiş olması bu durumu desteklemektedir. 
Lighthouse analizi sonucunda ortaya çıkan raporda, iyileştirmelerin nasıl uygulanacağı konusunda detaylı öneri ve belgeler bulunmaktadır. Buna ek olarak, sonuç bölümünde geliştiricilerin performanslarını daha da artırmak için keşfedebilecekleri ek kılavuzlara bağlantılar verilmiştir. Analiz sonuçları; 0-49 puan kırmızı renkte ve kötü, 50-89 puan turuncu renkte ve geliştirilmeye ihtiyacı olan, 90-100 puan ise iyi olarak kategorilendirilmiştir (Web.dev, 2020). Google tarafından paylaşılan belgeler ve ek klavuzlar, Lighthouse'u analiz aracı olmanın ötesine taşıyarak bir SEO uygulama rehberi haline getirmektedir. Yapılacak işlemlerin ne amaçla ve nasıl yapılacağı tüm bu dökümanlarda yer almaktadır.

\section{Yöntem}

\subsection{Araştırmanın amacı ve önemi}

Araştırmada, Google Lighthouse analiz aracının ölçtüğü SEO skoru ile arama motoru sonuç sayfalarında ortaya çıkan sıralama arasındaki ilişkinin tespit edilmesi amaçlanmıştır.

$\mathrm{Bu}$ araştırma işletmelerin SEO alanında pazarlama çabalarını ve bütçelerini en doğru faktörlere yöneltmesi açısından önem taşımaktadır. Ayrıca Lighthouse aracının, dolayısı ile bu aracı kullanan tüm işletmelerin dijital pazarlama stratejilerini geliştirilmelerine yönelik öneriler üretmektedir.

\subsection{Araştırmanın yöntemi}

Araştırmanın ilk aşamasında ölçüm yapılacak web sayfalarına ve anahtar kelimelere ihtiyaç duyulmuştur. Araştırmada kullanılacak anahtar kelimeler, Türkiye'de son bir yılda, alışveriş kategorisinde en çok aranan anahtar kelimeler arasından seçilmiştir. Anahtar kelimelere Google Trends analizi uygulanarak ulaşılmıştır. Google Trends analizi, yirmibeş adet anahtar kelime paylaşmaktadır. Elde edilen yirmibeş anahtar kelime arasında marka ve ürün isimleri bulunmaktadır. Marka isimleri Google'da arandığında sonuç sayfasında markaların kendi websitesi ile ilgili çok sayıda sonuçla karşılaşılmıştır. Ürün isimleri arandığında ise birbirinden farklı birçok web sayfasıyla karşılaşılmıştır. Bu nedenle araştırmada ürün isimleri kullanılmış ve daha çok sayıda web sayfasının analiz edilmesi mümkün kılınmıştır.

Ürün isimlerinden oluşan anahtar kelimeler Google Chrome tarayıcısında gizli sekme kullanılarak, çerezlerin etkisinde kalmadan Google'da aranmıştır. Organik arama sonuçlarında karşılaşılan ilk yirmi web sayfası Lighthouse aracı ile SEO analizine tabi tutulmuştur.

Analiz sonucunda ortaya çıkan SEO skorları ve sıralamalar anahtar kelime bazında tablolaştırılmıştır. Veri SPSS 23.00 programına aktarılmış ve Pearson korelasyon testi uygulanmıştır.

\section{Bulgular}

22.04.2020 tarihinde yapılan Google Trends analizi sonucunda son bir yılda alışveriş kategorisinde aranan en alakalı anahtar kelimeler Tablo 1'de verilmiştir.

Tablo 1. Google'da Son 12 Ayda Alışveriş Kategorisinde En Çok Aranan Anahtar Kelimeler

\begin{tabular}{|l|l|l|l|l|l|}
\hline Sıra & Anahtar Kelime & Sira & Anahtar Kelime & Sıra & Anahtar Kelime \\
\hline 1 & ayakkab1 & 11 & zara & 21 & bisiklet \\
\hline 2 & elbise & 12 & hepsi burada & 22 & spor ayakkab1 \\
\hline 3 & netflix & 13 & bim & 23 & gittigidiyor \\
\hline 4 & hepsiburada & 14 & koton & 24 & pegasus \\
\hline 5 & trendyol & 15 & flo & 25 & migros \\
\hline 6 & nike & 16 & abiye & & \\
\hline 7 & lcw & 17 & çanta & & \\
\hline 8 & saat saat & 18 & oyuncak & & \\
\hline 9 & adidas & 19 & hm & & \\
\hline 10 & saat & 20 & boyner & & \\
\hline
\end{tabular}

Kaynak: Google, (2020), Google arama istatistikleri, https://trends.google.com (Erişim tarihi: 22 Nisan 2020). 
D. Yüksel - K. Sümbültepe - M. Tolon 12/2 (2020) 2113-2125

Tablo 1. incelendiğinde marka isimleri hariç tutularak, sekiz adet ürün ismi tespit edilmiştir. Analizde kullanılacak anahtar kelimeler, ürün isimlerinden oluşmaktadır. Anahtar kelimeler ayakkabı, elbise, saat, abiye, çanta, oyuncak, bisiklet ve spor ayakkabı olarak belirlenmiştir. Ayakkabı ve spor ayakkabı anahtar kelimelerinde "ayakkabı" kelimesi tekrar edilmektedir ancak bu iki anahtar kelime Google'da ayrı ayrı arandığında sonuçların değiştiği tespit edilmiştir. Bu sebeple, hem ayakkabı hem de spor ayakkabı araştırmada farklı iki anahtar kelime olarak kullanılmıştır. Seçilen anahtar kelimeler ile ilgili Google Lighthouse ile elde edilen analiz sonuçları, Url (web sayfası adresleri) ve SEO skorları aşağıdaki tablolarda anahtar kelime bazında gösterilmiştir.

Tablo 2. "ayakkabı" Anahtar Kelimesi URL (Web Sayfası), Sıralama ve SEO Skoru Analiz Sonuçları

\begin{tabular}{|c|c|c|}
\hline \multicolumn{3}{|c|}{ Anahtar kelime: ayakkabı } \\
\hline Sira & URL (Web sayfası) & SEO Skoru \\
\hline 1 & flo.com.tr/ayakkabi & 85 \\
\hline 2 & ayakkabidunyasi.com.tr/ & 90 \\
\hline 3 & instreet.com.tr/ayakkabi & 89 \\
\hline 4 & morhipo.com/ayakkabi & 96 \\
\hline 5 & boyner.com.tr/kadin-ayakkabi-modelleri-c-1004 & 100 \\
\hline 6 & hepsiburada.com/bayan-ayakkabilar-c-60000116 & 88 \\
\hline 7 & trendyol.com/ayakkabi & 69 \\
\hline 8 & deichmann.com/TR/tr/shop/welcome.html & 87 \\
\hline 9 & elleshoes.com/bayan-ayakkabi & 92 \\
\hline 10 & hotic.com.tr/ & 91 \\
\hline 11 & superstep.com.tr/kadin-ayakkabi/ & 91 \\
\hline 12 & superstep.com.tr/kadin-spor-ayakkabi/ & 91 \\
\hline 13 & korayspor.com/ayakkabi/ & 91 \\
\hline 14 & ninewest.com.tr/ayakkabi & 91 \\
\hline 15 & sportive.com.tr/kadin-ayakkabi & 91 \\
\hline 16 & tergan.com.tr/kadin-ayakkabi & 91 \\
\hline 17 & twist.com.tr/ayakkabi/ & 91 \\
\hline 18 & $\underline{\text { lidyana.com/ayakkabi }}$ & 96 \\
\hline 19 & mudo.com.tr/ayakkabi-1/ & 98 \\
\hline 20 & lufian.com/erkek-ayakkabi-modelleri & 91 \\
\hline
\end{tabular}

Tablo 3. "elbise" Anahtar Kelimesi URL (Web Sayfası), Sıralama ve SEO Skoru Analiz Sonuçları

\begin{tabular}{|c|l|c|}
\hline \multicolumn{2}{|l|}{ Anahtar kelime: elbise } & SEO Skoru \\
\hline S1ra & URL (Web sayfası) & 69 \\
\hline $\mathbf{1}$ & $\underline{\text { trendyol.com/elbise }}$ & 82 \\
\hline $\mathbf{2}$ & $\underline{\text { denizbutik.com/elbise-modelleri }}$ & 96 \\
\hline $\mathbf{3}$ & $\underline{\text { morhipo.com/kadin-elbise }}$ & 89 \\
\hline $\mathbf{4}$ & $\underline{\text { oxxo.com.tr/tr/giyim/elbiseler/ }}$ & 89 \\
\hline $\mathbf{5}$ & $\underline{\text { hepsiburada.com/elbiseler-c-12087202 }}$ & 92 \\
\hline $\mathbf{6}$ & $\underline{\text { https://m.koton.com/tr/kadin/giyim/elbise/c/M01-C02-N01-AK103 }}$ & 76 \\
\hline $\mathbf{7}$ & $\underline{\text { bsl.com.tr/tr/koleksiyon/elbise/ }}$ & 80 \\
\hline $\mathbf{8}$ & $\underline{\text { https://www2.hm.com/tr tr/kadin/urune-gore-satin-al/elbise.html }}$ & \\
\hline
\end{tabular}


D. Yüksel - K. Sümbültepe - M. Tolon 12/2 (2020) 2113-2125

\begin{tabular}{|c|l|c|}
\hline $\mathbf{9}$ & ipekyol.com.tr/giyim/elbise-modelleri/ & 91 \\
\hline $\mathbf{1 0}$ & https:/m.defacto.com.tr/kadin-elbise & 99 \\
\hline $\mathbf{1 1}$ & tozlu.com/TR/kadin-elbise & 89 \\
\hline $\mathbf{1 2}$ & $\underline{\text { lcwaikiki.com/tr-TR/TR/kategori/kadin/elbise }}$ & 91 \\
\hline $\mathbf{1 3}$ & $\underline{\text { 5in1canpolat.com/elbise-10 }}$ & 91 \\
\hline $\mathbf{1 4}$ & $\underline{\text { https://shop.mango.com/tr/kadin/elbise_c55363448 }}$ & 95 \\
\hline $\mathbf{1 5}$ & $\underline{\text { mudo.com.tr/elbise/ }}$ & 98 \\
\hline $\mathbf{1 6}$ & $\underline{\text { mavi.com/kadin/elbise/c/1 }}$ & 97 \\
\hline $\mathbf{1 7}$ & $\underline{\text { cappmoda.com/elbise-modelleri }}$ & 89 \\
\hline $\mathbf{1 8}$ & $\underline{\text { adl.com.tr/c/elbise-858 }}$ & 97 \\
\hline $\mathbf{1 9}$ & $\underline{\text { lafaba.com/elbise }}$ & 99 \\
\hline $\mathbf{2 0}$ & vakkorama.com.tr/kadin-elbise & 99 \\
\hline
\end{tabular}

Tablo 4. "saat" Anahtar Kelimesi URL (Web Sayfası), Sıralama ve SEO Skoru Analiz Sonuçları

\begin{tabular}{|c|l|c|}
\hline \multicolumn{2}{|l|}{ Anahtar kelime: saat } & SEO Skoru \\
\hline S1ra & URL (Web sayfası) & 80 \\
\hline $\mathbf{1}$ & $\underline{\text { saatvesaat.com.tr/ }}$ & 98 \\
\hline $\mathbf{2}$ & $\underline{\text { kosovalisaat.com/ }}$ & 79 \\
\hline $\mathbf{3}$ & $\underline{\text { hepsiburada.com/saatler-c-318242 }}$ & 92 \\
\hline $\mathbf{4}$ & edipsaat.com/saat/ & 92 \\
\hline $\mathbf{5}$ & gittigidiyor.com/saat & 91 \\
\hline $\mathbf{6}$ & $\underline{\text { https://m.n11.com/saat }}$ & 92 \\
\hline $\mathbf{7}$ & $\underline{\text { konyalisaat.com.tr/ }}$ & 89 \\
\hline $\mathbf{8}$ & $\underline{\text { https://saatkac.info.tr/ }}$ & 69 \\
\hline $\mathbf{9}$ & $\underline{\text { trendyol.com/saat }}$ & 88 \\
\hline $\mathbf{1 0}$ & $\underline{\text { lidyana.com/saat }}$ & 100 \\
\hline $\mathbf{1 1}$ & $\underline{\text { boyner.com.tr/kadin-saat-modelleri-c-100602 }}$ & 96 \\
\hline $\mathbf{1 2}$ & $\underline{\text { morhipo.com/erkek-kol-saati }}$ & 92 \\
\hline $\mathbf{1 3}$ & $\underline{\text { hizlisaat.com/ }}$ & 62 \\
\hline $\mathbf{1 4}$ & $\underline{\text { upwatch.com/saat }}$ & 82 \\
\hline $\mathbf{1 5}$ & $\underline{\text { https://m.modanisa.com/saat.htm }}$ & 99 \\
\hline $\mathbf{1 6}$ & $\underline{\text { ciceksepeti.com/hediye-saat }}$ & 88 \\
\hline $\mathbf{1 7}$ & $\underline{\text { cimri.com/saat }}$ & 97 \\
\hline $\mathbf{1 8}$ & $\underline{\text { samilsaat.com/ }}$ & 96 \\
\hline $\mathbf{1 9}$ & $\underline{\text { ersasaat.com.tr/erkek-saat }}$ & 96 \\
\hline $\mathbf{2 0}$ & zenpirlanta.com/pirlantali-saatler & \\
\hline
\end{tabular}


D. Yüksel - K. Sümbültepe - M. Tolon 12/2 (2020) 2113-2125

Tablo 5. "abiye" Anahtar Kelimesi URL (Web Sayfası), Sıralama ve SEO Skoru Analiz Sonuçları

\begin{tabular}{|c|c|c|}
\hline \multicolumn{3}{|c|}{ Anahtar kelime: abiye } \\
\hline Sira & URL (Web sayfası) & SEO Skoru \\
\hline 1 & denizbutik.com/abiye- 60 & 89 \\
\hline 2 & olegcassini.com.tr/abiye & 89 \\
\hline 3 & $\underline{\text { saten.com/abiye }}$ & 90 \\
\hline 4 & abiyefon.com/abiye-modelleri & 100 \\
\hline 5 & patirti.com/kadin-abiye & 91 \\
\hline 6 & morhipo.com/kadin-abiye-elbise & 96 \\
\hline 7 & carmen.com.tr/abiye & 92 \\
\hline 8 & trendyol.com/abiye-elbise & 69 \\
\hline 9 & tugbavenn.com/abiye & 92 \\
\hline 10 & perspective.com.tr/abiye & 100 \\
\hline 11 & roman.com.tr/kategori/abiye-elbise- 4334 & 91 \\
\hline 12 & https://dugun.com/abiye-ve-nisanlik/ankara & 92 \\
\hline 13 & hepsiburada.com/abiye-elbiseler-c-12024561 & 79 \\
\hline 14 & pierrecardin.com.tr/kadin-elbise/ & 89 \\
\hline 15 & https://m.modanisa.com/tesettur-abiye.htm & 90 \\
\hline 16 & secilstore.com/abiye & 99 \\
\hline 17 & lidyana.com/abiye-elbise & 96 \\
\hline 18 & $\underline{\text { lafaba.com/abiye-elbise }}$ & 99 \\
\hline 19 & $\underline{\text { modaselvim.com/tesettur-abiye-elbise }}$ & 92 \\
\hline 20 & mayabutik.com/abiye-elbise & 92 \\
\hline
\end{tabular}

Tablo 6. "çanta” Anahtar Kelimesi URL (Web Sayfası), Sıralama ve SEO Skoru Analiz Sonuçları

\begin{tabular}{|c|l|c|}
\hline \multicolumn{2}{|l|}{ Anahtar kelime: çanta } & SEO Skoru \\
\hline Sıra & URL (Web sayfası) & 69 \\
\hline $\mathbf{1}$ & trendyol.com/kadin+canta & 100 \\
\hline $\mathbf{2}$ & boyner.com.tr/ayakkabi-canta-c-3390972 & 88 \\
\hline $\mathbf{3}$ & ecanta.com.tr/ & 87 \\
\hline $\mathbf{4}$ & matmazel.com/cantalar & 96 \\
\hline $\mathbf{5}$ & morhipo.com/kadin-canta & 92 \\
\hline $\mathbf{6}$ & $\underline{\text { https:/m.koton.com/tr/kadin/aksesuar/aksesuar/canta/c/M01- }}$ & 88 \\
\hline $\mathbf{7}$ & $\underline{\text { C02-N03-AK112-K100034 }}$ & 90 \\
\hline $\mathbf{8}$ & $\underline{\text { https://m.modanisa.com/canta.htm }}$ & 90 \\
\hline $\mathbf{9}$ & $\underline{\text { saten.com/kadin-canta }}$ & 92 \\
\hline $\mathbf{1 0}$ & $\underline{\text { addax.com.tr/aksesuar/canta/ }}$ & 89 \\
\hline $\mathbf{1 1}$ & pierrecardin.com.tr/kadin-canta-modelleri/ & 85 \\
\hline $\mathbf{1 2}$ & $\underline{\text { flo.com.tr/canta }}$ & 91 \\
\hline $\mathbf{1 3}$ & ninewest.com.tr/canta & 92 \\
\hline $\mathbf{1 4}$ & yargici.com/canta-cuzdan & \\
\hline
\end{tabular}


D. Yüksel - K. Sümbültepe - M. Tolon 12/2 (2020) 2113-2125

\begin{tabular}{|l|l|c|}
\hline $\mathbf{1 5}$ & desa.com.tr/kadin-canta/ & 83 \\
\hline $\mathbf{1 6}$ & tergan.com.tr/kadin-canta & 91 \\
\hline $\mathbf{1 7}$ & kayra.com/tr/canta & 92 \\
\hline $\mathbf{1 8}$ & https://shop.mango.com/tr/kadin/canta c18162733 & 96 \\
\hline $\mathbf{1 9}$ & zara.com/tr/tr/kadin-chantalar-11024.html & 98 \\
\hline $\mathbf{2 0}$ & kemaltanca.com.tr/canta-kadin/ & 89 \\
\hline
\end{tabular}

Tablo 7. "oyuncak" Anahtar Kelimesi URL (Web Sayfası), Sıralama ve SEO Skoru Analiz Sonuçları

\begin{tabular}{|c|c|c|}
\hline \multicolumn{3}{|c|}{ Anahtar kelime: oyuncak } \\
\hline Sira & URL (Web sayfasi) & SEO Skoru \\
\hline 1 & hepsiburada.com/oyuncaklar-c-23031884 & 89 \\
\hline 2 & gittigidiyor.com/oyuncak & 92 \\
\hline 3 & toyzzshop.com/ & 100 \\
\hline 4 & trendyol.com/oyuncak & 69 \\
\hline 5 & civilim.com/oyuncaklar & 92 \\
\hline 6 & joker.com.tr/oyuncak & 97 \\
\hline 7 & armaganoyuncak.com.tr/ & 81 \\
\hline 8 & https://m.n11.com/cocuk-oyuncaklari-ve-parti/oyuncak & 91 \\
\hline 9 & locopoco.com/oyuncak & 85 \\
\hline 10 & idefix.com/kategori/Hobi-Oyuncak & 91 \\
\hline 11 & dr.com.tr/kategori/Hobi-Oyuncak/Oyuncaklar/grupno=00098 & 99 \\
\hline 12 & babymall.com.tr/kategori/bebek-oyuncaklari & 89 \\
\hline 13 & morhipo.com/cocuk-oyuncak & 96 \\
\hline 14 & amazon.com.tr/s?i=toys\&rh=n\%3A12467126031 & 100 \\
\hline 15 & tchibo.com.tr/m/oyuncak-c400089101.html & 99 \\
\hline 16 & migros.com.tr/oyuncaklar-c-9e & 90 \\
\hline 17 & akakce.com/oyuncak.html & 92 \\
\hline 18 & lcwaikiki.com/tr-TR/TR/kategori/kiz-cocuk/oyuncak-ve-kirtasiye & 91 \\
\hline 19 & e-bebek.com/bebek-oyuncaklari-c3776/ & 100 \\
\hline 20 & a101.com.tr/anne-bebek/bebek-oyuncaklari-hediyelik/ & 98 \\
\hline
\end{tabular}

Tablo 8. "bisiklet” Anahtar Kelimesi URL (Web Sayfası), Sıralama ve SEO Skoru Analiz Sonuçları

\begin{tabular}{|c|l|c|}
\hline \multicolumn{2}{|l|}{ Anahtar kelime: bisiklet } & SEO Skoru \\
\hline S1ra & URL (Web sayfası) & 89 \\
\hline $\mathbf{1}$ & $\underline{\text { hepsiburada.com/bisikletler-c-27026003 }}$ & 92 \\
\hline $\mathbf{2}$ & gittigidiyor.com/bisiklet/bisiklet & 100 \\
\hline $\mathbf{3}$ & $\underline{\text { bisikletcim.com/ }}$ & 91 \\
\hline $\mathbf{4}$ & $\underline{\text { https://m.n11.com/bisiklet-ve-scooter }}$ & 100 \\
\hline $\mathbf{5}$ & $\underline{\text { http://bianchi.com.tr/ }}$ & 69 \\
\hline $\mathbf{6}$ & $\underline{\text { trendyol.com/bisiklet }}$ & 90 \\
\hline $\mathbf{7}$ & $\underline{\text { deltabisiklet.com/ }}$ & 90.00 \\
\hline
\end{tabular}


D. Yüksel - K. Sümbültepe - M. Tolon 12/2 (2020) 2113-2125

\begin{tabular}{|c|l|c|}
\hline $\mathbf{8}$ & decathlon.com.tr/C-528932-bisiklet-modelleri\#product 8501699 & 99 \\
\hline $\mathbf{9}$ & akakce.com/bisiklet.html & 92 \\
\hline $\mathbf{1 0}$ & $\underline{\text { cimri.com/bisikletler }}$ & 89 \\
\hline $\mathbf{1 1}$ & sahibinden.com/bisiklet\#/ & 92 \\
\hline $\mathbf{1 2}$ & aslibisiklet.com/bisikletler-3968 & 83 \\
\hline $\mathbf{1 3}$ & bisiklet.com/ & 97 \\
\hline $\mathbf{1 4}$ & umitbisiklet.com.tr/ & 100 \\
\hline $\mathbf{1 5}$ & vatanbilgisayar.com/bisiklet/ & 91 \\
\hline $\mathbf{1 6}$ & http://www.kackarbisiklet.com/k/bisiklet/ & 94 \\
\hline $\mathbf{1 7}$ & cimri.com/bisiklet & 89 \\
\hline $\mathbf{1 8}$ & ozceylanbisiklet.com/kategori/bisiklet & 92 \\
\hline $\mathbf{1 9}$ & alcbisiklet.com/kategori/bisiklet & 83 \\
\hline $\mathbf{2 0}$ & atekbisiklet.com/kategori/bisiklet & 83 \\
\hline
\end{tabular}

Tablo 9. "spor ayakkabı" Anahtar Kelimesi URL (Web Sayfası), Sıralama ve SEO Skoru Analiz Sonuçları

\begin{tabular}{|c|c|c|}
\hline \multicolumn{3}{|c|}{ Anahtar kelime: spor ayakkabı } \\
\hline Sira & URL (Web sayfası) & SEO Skoru \\
\hline 1 & flo.com.tr/spor-ayakkabi?cinsiyet=erkek & 85 \\
\hline 2 & sportive.com.tr/erkek-ayakkabi & 91 \\
\hline 3 & hepsiburada.com/spor-ayakkabilar-c-384551 & 89 \\
\hline 4 & korayspor.com/erkek-spor-ayakkabi/ & 91 \\
\hline 5 & instreet.com.tr/spor-ayakkabi & 90 \\
\hline 6 & superstep.com.tr/kadin-spor-ayakkabi/ & 91 \\
\hline 7 & morhipo.com/erkek-spor-ayakkabi & 96 \\
\hline 8 & trendyol.com/erkek+spor-ayakkabi & 69 \\
\hline 9 & ayakkabidunyasi.com.tr/erkek-spor-ayakkabilar/ & 97 \\
\hline 10 & barcin.com/kadin-spor-ayakkabi/ & 92 \\
\hline 11 & lescon.com.tr/erkek-spor-ayakkabi/ & 90 \\
\hline 12 & n11.com/spor-giyim-ve-ayakkabi/spor-ayakkabi & 91 \\
\hline 13 & sneaksup.com.tr/erkek-sneaker-ayakkabi & 91 \\
\hline 14 & $\underline{\text { dalkilicspor.com/erkek-spor-ayakkabi }}$ & 100 \\
\hline 15 & dalkilicspor.com/ & 100 \\
\hline 16 & $\begin{array}{l}\text { gittigidiyor.com/ayakkabi-sandalet-terlik/spor- } \\
\text { ayakkabi?kullanici-tipi=Erkek }\end{array}$ & 91 \\
\hline 17 & cimri.com/spor-ayakkabi & 89 \\
\hline 18 & kemaltanca.com.tr/erkek-sneakers-spor/ & 89 \\
\hline 19 & modatrend.com.tr/bayan-spor-ayakkabi & 92 \\
\hline 20 & defacto.com.tr/erkek/ayakkabi-spor-ayakkabi?lt=v1 & 91 \\
\hline
\end{tabular}

Her bir sıralamada elde edilen SEO skorlarının ortalaması alınarak Tablo 10. oluşturulmuştur. Araştırmada kullanılan anahtar kelimelerin tamamında, seçilen sırada bulunan web sayfalarının SEO skorlarının ortalaması alınmıştır. Bu işlem yirmi sıra için ayrı ayrı uygulanmıştır. 
D. Yüksel - K. Sümbültepe - M. Tolon 12/2 (2020) 2113-2125

Tablo 10. Siralamaların Ortalama SEO Puanları Tablosu

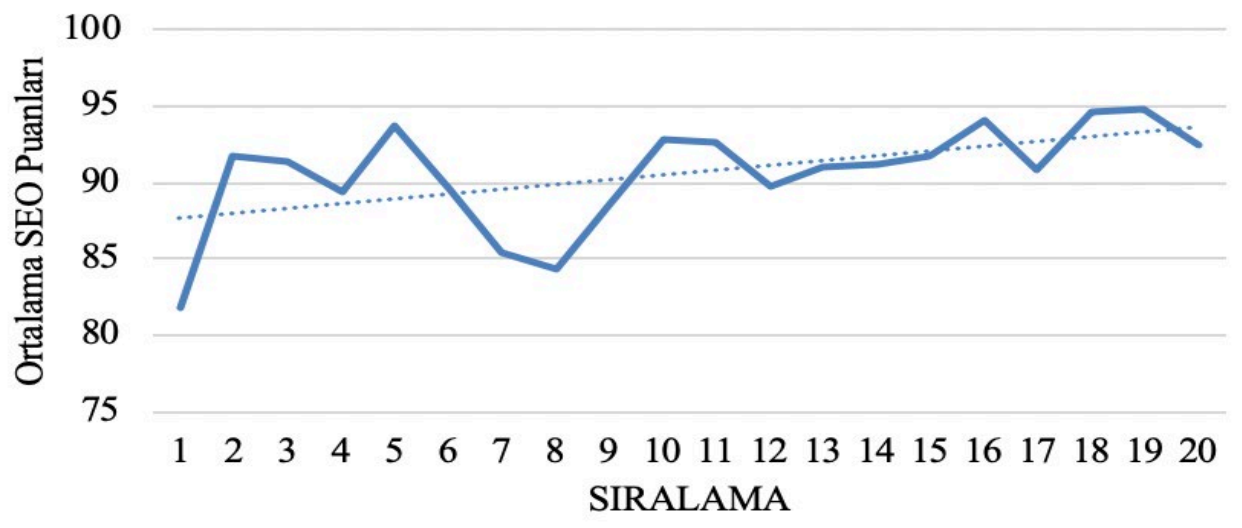

— Ortalama SEO Skoru …..... Doğrusal Eğilim Çizgisi

Veri Microsoft Excel programında görselleştirilmiştir. Veri ışığında bir doğrusal eğilim ekseni oluşturulmuştur. Eğilim ekseni Google'da 1. sıradan 20. sıraya doğru gidildikçe SEO skorunun arttığını göstermektedir.

Tüm gruplarda $n>30$ olduğu için, verinin normal dağılıma yakınsanacağ varsayımına dayanarak parametrik testlerin kullanılması mümkündür (Kul, 2014: 28; Ovla vd., 2017: 243; aktaran Özel vd., 2004). SEO puanı ve sıralama arasındaki ilişkiyi değerlendirmek üzere Pearson korelasyon analizi gerçekleştirilmiştir.

Korelasyon analizi sonucunda ortaya çıkan SPSS grafiği Microsoft Excel programında Tablo 11'de görselleştirilmiştir.

Tablo 11. SEO Skoru ve Sıralama Korelasyon Veri Dağılımı

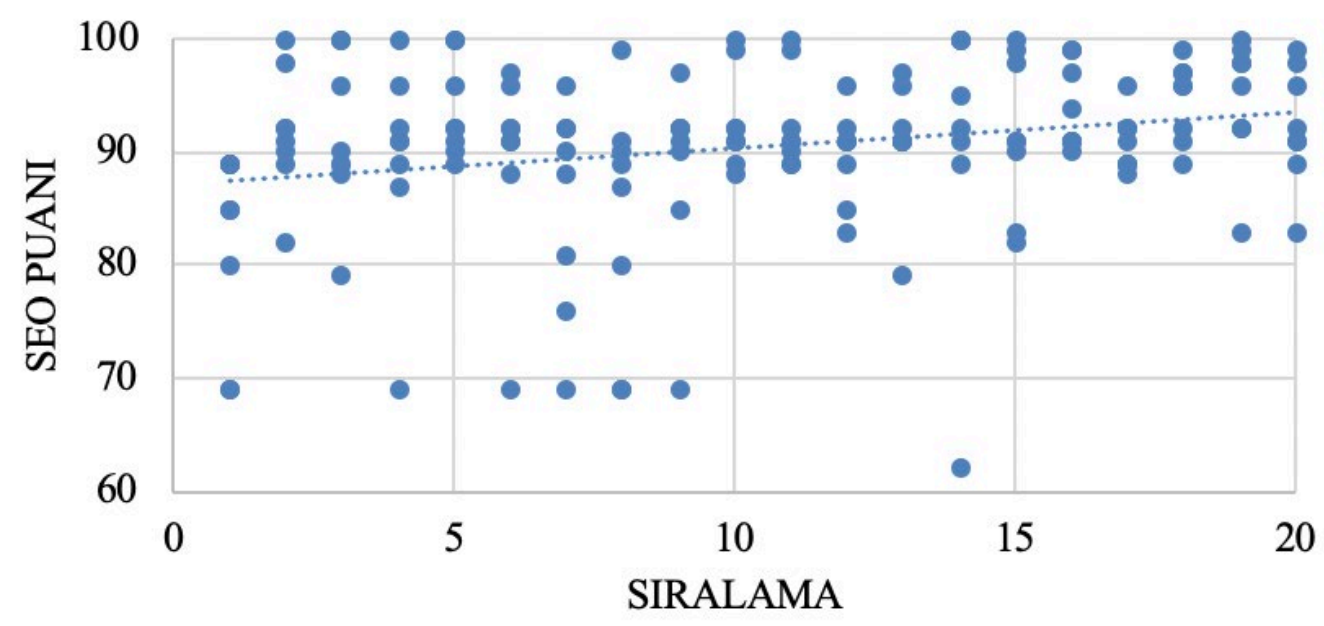

- SEO Skoru ……. Doğrusal Eğilim Çizgisi

Verinin doğrusala yakın bir eğilim çizgisinin etrafında toplanması zayıf bir korelasyonun bulunduğunu göstermektedir.

SPSS 23.00 analiz programında uygulanan Pearson korelasyon analizi sonuçları Tablo 12' de gösterilmiştir. 
D. Yüksel - K. Sümbültepe - M. Tolon 12/2 (2020) 2113-2125

Tablo 12. SPSS v23.00 Korelasyon Analiz Sonuç Tablosu

\begin{tabular}{|ll|c|c|}
\hline SEO & Pearson Korelasyon & 1 &, $245^{* *}$ \\
& $\mathrm{p}$ & &, 002 \\
& $\mathrm{~N}$ & 160 & 160 \\
\hline SIRALAMA & Pearson Korelasyon &, $245^{* *}$ & 1 \\
& $\mathrm{p}$ &, 002 & 160 \\
\hline
\end{tabular}

${ }^{* *}$ Correlation is significant at the 0.01 level (2-tailed).

Korelasyon analizinde p değeri 0,01 olarak elde edilmiştir. P değerinin 0,01'ten küçük olması, yapılan testin anlamlı ve yorumlanabilir olduğunu göstermektedir.

Analiz sonucunda $r$ değerinin ise 0,245 olarak elde edilmiş olması, iki değişken arasında zayıf bir korelasyonun olduğu anlamına gelmektedir (Zou vd., 2003). Arama motorlarında birinci sıra en değerli konumdur. Sıralama birden yirmiye doğru arttıkça konumun değeri düşmektedir. Bu nedenle, sıralama ile SEO skoru arasındaki ilişkinin yönü negatif olarak yorumlanmalıdır.

Kullanılan anahtar kelimeler ile sonuç sayfalarında karşılaşılan web sayfalarının URL yapısında, anahtar kelimenin bulunup bulunmama durumu Tablo 13'te Microsoft Excel programı kullanılarak pasta grafiği ile görselleştirilmiştir.

Tablo 13. URL ve Anahtar Kelime Eşleşme Tablosu

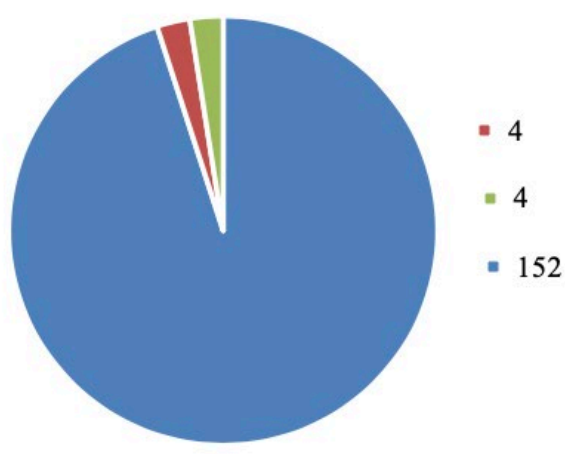

- URL'de anah tar kelime bulunuyor.

- URL'de anah tar kelimen in ingilizcesi bulunuyor.

- URL'de anahtar kelime bulunmuyor.

Yapılan araştırma sonucunda analize tabi tutulan 160 sayfanın 152'sinde anahtar kelimenin, 4'ünde anahtar kelimenin İngilizcesinin bulunduğu tespit edilmiştir. Sadece 4 web sayfasının URL yapısında anahtar kelimeye rastlanmamıştır. İşletmelerin SEO çalışmalarında, web sayfalarının URL yapılarını odaklandıkları anahtar kelimelere uygun bir şekilde düzenlenmesinin etkili bir yöntem olduğu tespit edilmiştir. 


\section{Sonuç ve Tartışma}

Çalışmada Google'ın geliştirdiği Lighthouse aracı hakkında önemli bulgular elde edilmiş ve yorumlanmıştır. Konu hakkında çeşitli öneriler geliştirilmiştir.

Google Lighthouse SEO skoruyla, sıralama arasında zayıf bir korelasyon bulunduğu tespit edilmiştir. Korelasyonun zayıf olması, SEO skoru ile sıralama arasında düşük bir ilişkinin olduğuna işaret etmektedir. Bulgular anahtar kelime bazında incelendiğinde, SEO puanı 69 olan bir web sayfası birinci sırada yer alırken, 99 puan olan başka bir web sayfasının yirminci sırada yer aldığı çarpıcı örneklere çokça rastlanmıştır. Bunun gibi örnekleri çoğaltmak mümkündür. Dolayısıyla Lighthouse tarafından ölçülen SEO faktörlerinin, sıralama açısından önemli bir etkisinin olmadığı sonucuna ulaşılmıştır.

Analizin uygulandığı anahtar kelimelerde, SEO skoru yüksek olan web sayfalarının daha alt sıralarda kümelendiği ortaya çıkmıştır. Buna karşın SEO skoru düşük olan web sayfalarının ise üst sıralarda kümelendiği görülmüştür. SEO skoru ile sıralama arasında negatif yönlü bir ilişkinin olduğu tespit edilmiştir. Bulgular SEO skorunun düşük olmasını olumlu bir durum olarak göstermemelidir. İlişkinin zayıf olması bu durumu anlamsız kılmaktadır.

Lighthouse analiz aracı site içi SEO faktörlerini ölçümlemektedir. İlişkinin zayıf olduğu değerlendirildiğinde, site dışı SEO faktörlerinin site içi SEO faktörlerinden daha değerli olduğu varsayımında bulunulmuştur.

Google, sıralama algoritmasını gizli tutmaktadır. Bu durum göz önünde bulundurulduğunda analiz aracının ölçüm algoritması ve faktörlerinin Google sıralama algoritmasına daha uygun bir şekilde geliştirilmesi ve değiştirilmesi önerilmektedir. Bu sayede, Lighthouse analiz aracı ile sıralama arasındaki ilişki artacak ve analiz sonuçları daha anlamlı hale gelecektir.

Elde edilen bulgular 1şığında Lighthouse SEO skoru 100 ve 100 puana yakın olan işletmelerin bu puan ile yetinmemeleri ve güncel SEO stratejilerini takip etmeleri, keşfetmeleri ve uygulamaları tavsiye edilmektedir.

Google tarafından oluşturulmuş bir analiz aracı yetkin ve güvenilir olarak değerlendirilebilir ancak sayısız SEO faktörünün olması her analiz aracının birbirinden farklı faktörleri ölçmesine yol açmışıı. İşletmeler SEO çalışmalarını gerçekleştirirken, Lighthouse dışındaki analiz araçlarından da faydalanmalı ve daha fazla faktörün analizini gerçekleştirerek daha yüksek performansa sahip sayfalar elde etmelidir.

Araştırma yapılırken, tüm URL yapılarının \%95'inde anahtar kelimenin, \%2,5'inde ise anahtar kelimenin ingilizce karşılığının bulunduğu tespit edilmiştir. Bu durum URL yapısında anahtar kelime kullanmanın önemli bir SEO faktörü olduğunu doğrular niteliktedir. SEO çalışması yapılan sayfaların URL yapıları, odaklanılan anahtar kelimeyi içerecek şekilde düzenlenmelidir. Yeni bir sayfa oluşturulurken de odaklanılan anahtar kelimeleri içeren URL yapıları oluşturulmalıdır. Tek bir URL yapısı kullanmak yerine içerikler farklı URL yapıları altında çeşitlendirilmelidir. Örneğin, /ayakkabi URL'sine ek olarak /erkek-ayakkabi, /kadinayakkabi, /çocuk-ayakkabi gibi çeşitli anahtar kelimeleri tetikleyen yapılar ortaya koyulmalıdır.

Yapılan bu araştırmanın kısıtlılıkları aşağıda maddeler halinde verilmiştir;

- Google Trends analizi son bir yılda, Türkiye'de gerçekleştirilen arama sonuçlarında maksimum 25 anahtar kelimeyi sonuçlarında göstermektedir. Seçilen anahtar kelimeler bu liste ile sınırlı tutulmuştur.

- Elde edilen 25 anahtar kelime arasında çeşitli marka isimleri bulunmaktadır. Marka isimleri Google'da arandığında sonuçların büyük bir kısmı markaların kendi web sayfalarından oluşmaktadır. Bu nedenle tutarlı bir analizin yapılabilmesi için marka isimleri listeden çıkartılmış ve liste, ürün isimleri ile sinırlı tutulmuştur.

- Lighthouse analizi, mobil web sayfalarının ölçümü ile kısıtlı tutulmuştur.

Gelecekte yapılacak çalışmalarda, teknoloji, giyim, oyun gibi alışverişin alt kategorilerinde, farklı anahtar kelimeler kullanılması, yapılan araştırmanın kapsamını genişletebilecektir. Ayrıca teknolojinin çok hızlı gelişmesi nedeniyle Google algoritmasında ve analiz araçlarında sıklıkla güncellemeler yapılmaktadır. Bu güncellemeleri ve teknolojik gelişmeleri takip edebilmek adına yapılan araştırmanın belirli aralıklarla tekrarlanması önerilmektedir. 


\section{KAYNAKLAR}

Atay, C., Alanyall, M., Uyan, S. B. ve Baş, C. (2010). Arama Motoru Optimizasyonu, Akademik Bilişim 2010. XII. Akademik Bilişim Konferansı Bildirileri, Muğla, Türkiye, Muğla Üniversitesi, 10-12 Şubat 2010, 10-12.

Baeza-Yates, R., Gionis, A., Junqueira, F., Murdock, V., Plachouras, V., and Silvestri, F. (2007). The impact of caching on search engines, in Proceedings of the 30th annual international ACM SIGIR conference on Research and development in information retrieval, in Amsterdam, Netherlands, 23-27 July 2007, 183-190.

Berman, R., and Katona, Z. (2013). The role of search engine optimization in search marketing, Marketing Science, 32(4), 644-651.

De Corniere, A. (2016). Search advertising, American Economic Journal: Microeconomics, 8(3), 156-88.

Dunford II, T. (2008). Advanced Search Engine Optimization A Logical Approach, Wailuku, American Creations of Maui.

Google Trends (2020), Google arama istatistikleri https://trends.google.com/ (Erişim tarihi: 22 Nisan 2020).

Höchstötter, N. and Lewandowski, D. (2009). What Users See-Structures in Search Engine Results Pages, Information Sciences, 179(12), 1796-1812.

Kul, S. (2014). Uygun İstatistiksel Test Seçim Kılavuzu/Guideline For Suitable Statistical Test Selection, Plevra Bülteni, 8(2), 26.

Google, (2019). Lighthouse, https://developers.google.com/web/tools/lighthouse_(Erişim tarihi: 15 Şubat 2020).

Nadire, Özel, Kalaycı, S., Sevimli, M. F. ve Büyükyıldız, M. (2004). Sakarya Nehri Havzası Aylık Akım Verilerinin Parametrik Olmayan Yöntemlerle Trend Analizi, Selçuk Üniversitesi Mühendislik, Bilim ve Teknoloji Dergisi, 19(2), 11-22.

Ochoa, E. D. (2012). Analysis of The Application of Selected Search Engine Optimization (SEO) Techniques And Their Effectiveness on Google's Search Ranking Algorithm (Doctoral Dissertation, California State University, Northridge).

Ovla, D. H., Türkegün, M., Özdemir, A. A., Özcömert, B. V. ve Taşdelen, B. (2017). Parametrik Olmayan Yöntemlerin Yanlış Kullanımı ve Doğurabileceği Sonuçlar: Simülasyon Çalışması, Cukurova Medical Journal, 42(2), 241-248.

Seymour, T., Frantsvog, D. and Kumar, S. (2011). History of Search Engines, International Journal of Management \& Information Systems (IJMIS), 15(4), 47-58.

Statista. (2020), https://www.statista.com/topics/1710/search-engine-usage/ (Erişim tarihi: 10 Haziran 2020).

Vuran, E. G., ve Alpkoçak, A. (2020). Arama Motoru Optimizasyon Yöntemlerinin Analizi, Dokuz Eylül Üniversitesi Mühendislik Fakültesi Fen ve Mühendislik Dergisi, 22(65), 491-503.

Yüksel, D. ve Tolon, M. (2019). Dijital Pazarlama Stratejisi Olarak Arama Motoru Optimizasyonu (SEO), International Journal of 3D Printing Technologies and Digital Industry, 3(3), 236-243.

Zilincan, J. (2015). Search engine optimization, in CBU International Conference Proceedings, in Prague, Czech Republic,25-27 March 2015, 506-510.

Zou, K. H., Tuncali, K., and Silverman, S. G. (2003). Correlation and simple linear regression, Radiology, 227(3), 617-628.

Web.dev, (2019). Lighthouse performance scoring, https://web.dev/performance-scoring/ (Erişim tarihi: 17 Haziran 2020). 